\title{
DEVELOPMENT OF NUMERICAL MODEL AND COMPARISON WITH THE ANALYTICAL MODEL FOR PREDICTING THE WIRE EFFECTS IN WIRE ELECTRIC DISCHARGE GRINDING
}

\author{
MADHAVADEV Parthiban', ${ }^{1}$ IJJAYAN Krishnaraj ${ }^{1}$, MOULEESWARAN Senthilkumar ${ }^{2}$ \\ ${ }^{1}$ Department of Mechanical Engineering, PSG College of Technology, Coimbatore 641004, India, \\ ${ }^{2}$ Department of Production Engineering, PSG College of Technology, Coimbatore 641004, India, \\ email:msk.prod@psgtech.ac.in
}

\begin{abstract}
This paper discusses the development of a numerical model and its comparison with the analytical model to predict the wire deflection in WEDG. The movement of wire between upper and lower guides creates vibration during the machining process which can create micro deflection of the wire. The Finite Element Analysis model [FEA] for the wire deflection is analyzed and compared with the analytical model. The deflection of the wire due to the input current may affect the machining of micro parts, which will be used for further research in micro machining and also will help us to choose the parameters such as current, spark gap, wire feed, and the speed of the workpiece during micro machining with WEDG. The FEA results for various forces were compared with the analytical results and found that the developed numerical model results are in good agreement.
\end{abstract}

KEYWORDS: FEA; WEDG; deflection; vibration; analytical

\section{Introduction}

The Wire Electric Discharge Machining is a non-conventional machining process, in which a conductive wire (tool electrode) travels between the top and bottom guides, the work material is placed in between (also a conductive material- work electrode) is placed, as shown in Figure 1. While the powers supplied to the wire, the gap between the wire and the workpiece produces thermal energy and removes the unwanted work material. The desired shape can be obtained by moving the work table in X and Y directions. In the WEDG process, the tool never exerts the force on the work piece so that very hard to machine materials can be machined with ease. The main parameters that influence the production in the WEDG process are spark gap, voltage, current and the wire feed. The decrease in spark gap will lead to increase in the thermal energy, which will result in more material removal. Similarly, the higher voltage will lead to more material removal in the workpiece, which will improve the productivity. The rapid removal of work material may lead to dimensional inaccuracies. In order to maintain the dimensional accuracies of the components the voltage, the spark gap and the wire feed has to be proportional. Any complex shape can be easily generated with a high grade of accuracy and surface finish using computer numerical control. Customized software development has further strengthened process technology in improving geometrical and technological data of work piece. Applications of WEDG include manufacturing die and mold components like sheet metal press dies, extrusion dies, etc., prototype and special form inserts manufacturing [1]. Its broad capabilities have allowed it to encompass the production of aerospace/aircraft and medical industries and virtually all areas of conductive material machining. An analysis of the effect of various process parameters for achieving improved machining characteristics is required for successful utilization of process with high productivity [2]. 
However, in wire electrical discharge machining (WEDG), the cost of machining is rather high due to- a high initial investment for the machine and the cost of the wire which is used as a tool in this process. The WEDG process is economical if it is used to cut complex work pieces and difficult to machine materials where the wire electrical discharge grinding has occupied an important position in some high-precision and high-performance manufacturing industries due to its capability of accurate and efficient machining parts with varying hardness or complex shapes, the high-machining precision and efficiency, especially at rough corner cutting, cannot be satisfied simultaneously because of some phenomena such as wire rupture, deflection, vibration, etc.[3]. In WEDG process, as the wire moves from the top guide to bottom guide, there will be vibrations according to the amount of material removal. Because of vibrations, the spark gap will be varied due to which the material removal rate and the accuracy of the component may get affected. The prediction of the amplitude of vibration of the wire can control the material removal process and the accuracy of the component in WEDG. As newer and more exotic materials are developed, and more complex shapes are presented, conventional machining operations will continue to reach their limitations and the increased use of WEDG in manufacturing will continue to grow at an accelerated rate [4]. Hybrid machining using by WEDG has started to manufacture small pins, using a rotary axis setup which may be used as a tool for three dimensional electrical discharge machining (EDM) applications [5].

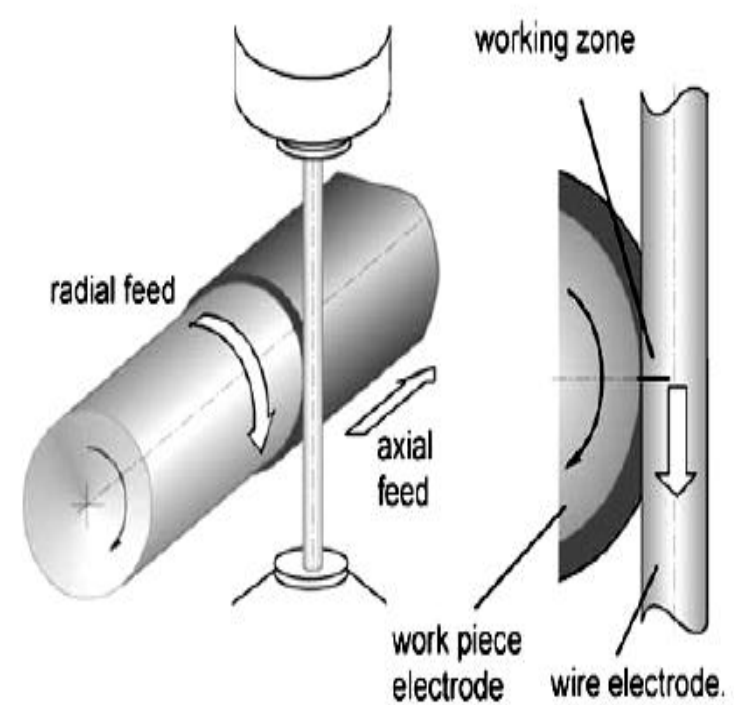

Fig. 1 WEDG Principle [5]

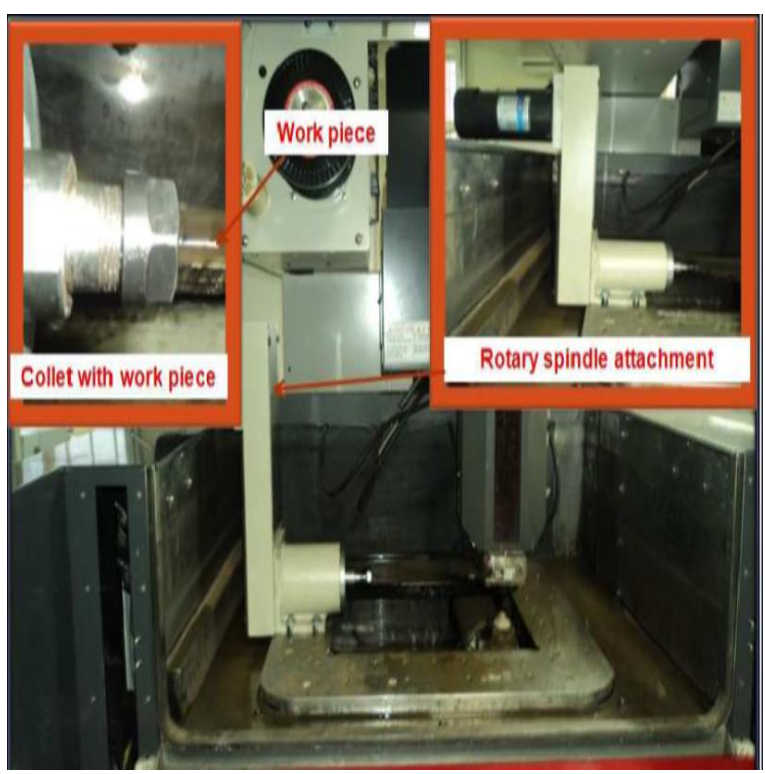

Fig. 2 Wire Electric Discharge Grinding Setup [14]

Grinding with WEDG is one of the emerging areas developed to generate a cylindrical form on hard and difficult to machine materials by adding a rotary axis to WEDG process [6]. Since our process set up as shown Figure $1 \mathrm{~b}$ which has been designed and fabricated and kept as an accessory with the existing CNC WEDM for machining of micro parts. For this, it becomes necessary to analyze the vibration response of the wire during the WEDG process. In the WEDG process the wire never touches the work piece for material removal but as it is the micro machining process the vibration response may act as a factor in selecting the machining parameters. In order to compute the vibration of the wire which will exert based on the input voltage, a model was drawn as shown in Figure 3. By keeping the guides as the fixed support and the wire as free the numerical model was analyzed with the help of Finite Element Analysis [FEA] software. The force that the, wire generates may be based upon the input voltage has been already derived by the research study [7]. Based on this study, the various forces were used for our study in the FEA model and the results were obtained. According to the WEDG specification there should not be any force in the wire as per the concept, wire never touches 
the work piece. Since we are doing the micro manufacturing even a very small force which exerts on the wire for the input current may cause some micro deflection in the wire. For the same a mathematical equation was arrived by considering several factors [7] and both the FEA results and the equation results were compared. Since there was not much deviation observed, a similar prototype micro-wire EDM setup was kept as a reference for the development of our study [8].

\section{The Wire-electrode (tool) Vibration and the Mathematical Model}

The vibration behaviour of the wire is extremely complicated in nature. The occurrence of spark is highly stochastic in nature, the magnitude and directions of the various forces acting along or upon the wire are not always constant. Moreover, while the wire is in vibration mode, sparks continue to occur in the extreme nodal positions of the wire [9]. The following main forces acting along the wire or upon the wire are, forces from the gas bubbles formed by the plasma of the erosion mechanism, hydraulic forces due to di-electric fluid movement, electrostatic force and electro-dynamic force. The hydraulic force will not be significant if the work is submerged in the di-electric medium, hence can be neglected. The wire experiences an impact during every individual spark discharge and acts in the reverse direction of the discharge occurrence. The schematic representation of wire (tool) vibration in WEDG process at normal condition is shown in Figure 3. The forces from the gas bubbles, electrostatic force, electrodynamic force and the axial tensile force of the wire due to tension will induce vibration to the wire when discrete sparks are generated between the tool and work piece electrodes. As the wire never touches the work piece there is no induced force during machining and the vibration force may vary depending on the work piece material and the input parameters.

The general partial differential equation of motion as per Newton's second law of motion for a stretched vibrating string of length $L$ in a plane (along $Z$-axis) is given in equation 1 [10].

$$
F \frac{\partial^{2} y}{\partial z^{2}}-E I \frac{\partial^{4} y}{\partial z^{4}}=\rho \frac{\partial^{2} y}{\partial t^{2}}+\beta \frac{\partial y}{\partial t} q(z, t)
$$

where, $F$ is wire tension in $(\mathrm{N}) ; y$ is wire deflection in $(\mathrm{m}), t$ is time in $(\mathrm{s}) ; \rho$ is wire mass density in $\left(\mathrm{kg} / \mathrm{m}^{3}\right) ; s$ is wire cross-section in $\left(\mathrm{m}^{2}\right) ; \beta$ is specific damping co-efficient of the wire, $E$ is Young's modulus in $\left(\mathrm{N} / \mathrm{m}^{2}\right) ; I$ is area moment of inertia, $d$ is wire diameter in $(\mathrm{m})$ and $q(z, t)$ is the specific external load or body force per unit length of the wire in $(\mathrm{N} / \mathrm{m})$.

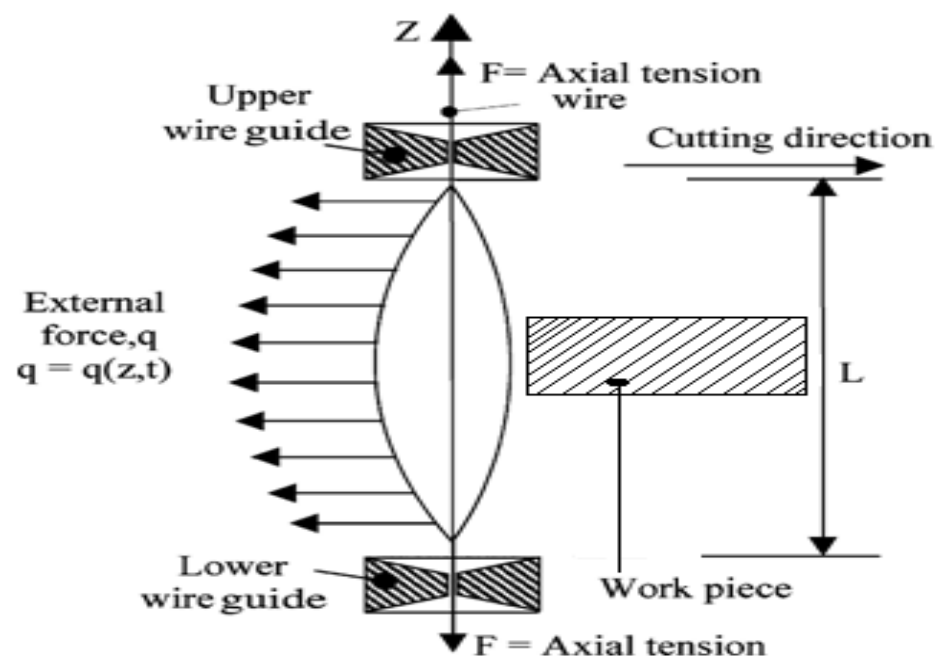

Fig. 3 Schematic diagram of wire vibration in WEDG [10] 
The 1st term indicates the force due to bending deflection because of the applied axial tension $F$. The 2 nd term represents the force required for transverse bending against the flexural rigidity of the wire, as the wire is assumed to be perfectly flexible, and will be negligibly small. The 3rd and 4th term represents the acceleration force according to Newton's second law of motion and damping force respectively. The above partial differential equation will give rise to the evaluation of the wire deflection, but the partial differential equations are highly complex to solve and the determination of the force $q(z, t)$ is also a difficult task. The analytical solutions for finding $y(z, t)$ is difficult using partial differential equations and requires a wide range of considerations of machining operational features to obtain a real-time solution. However, by using certain simplified assumptions, the complexity of the solution can be reduced and a feasible solution can be arrived by sacrificing a small percentage of accuracy and precision.

\section{Finite Element Analysis Validation}

In order to make Finite Element Analysis, the CAD model is created according to the specification with the use of Creo Parametric 2.0 software and the same is shown in Figure 4. Then the model has been converted into Initial Graphics Exchange Specification (IGES) file a standard format for importing the file to finite element software. The diameter of the brass wire is $0.25 \mathrm{~mm}$ and the length of wire between the guides is $100 \mathrm{~mm}$. The material properties of diamond for wire guide and brass for wire are taken as input for the finite element analysis.

After applying all the boundary conditions and the load data, the prediction of deflection of the wire electrode for the applying forces is shown in Figure 7. The force is given in both the $\mathrm{X}$ and $\mathrm{Y}$ directions as the wire will move only in the Z-direction. The Figures $8 \& 9$ were shown as samples for $0.002 \mathrm{~N}$ and $0.006 \mathrm{~N}$ force arbitrarily as during the trials, the wire got broken at $0.01 \mathrm{~N}$. The deflection of the wire found for the force ranging from $0.0005 \mathrm{~N}$ to $0.006 \mathrm{~N}$ at various levels is given in Table 1. In order to ensure the attained deflection data for its correctness, the mesh convergence plot has been plotted and is shown in Figure 10. More trials are taken by applying various forces and the attained deflection value for the respective force is listed in Table 1.

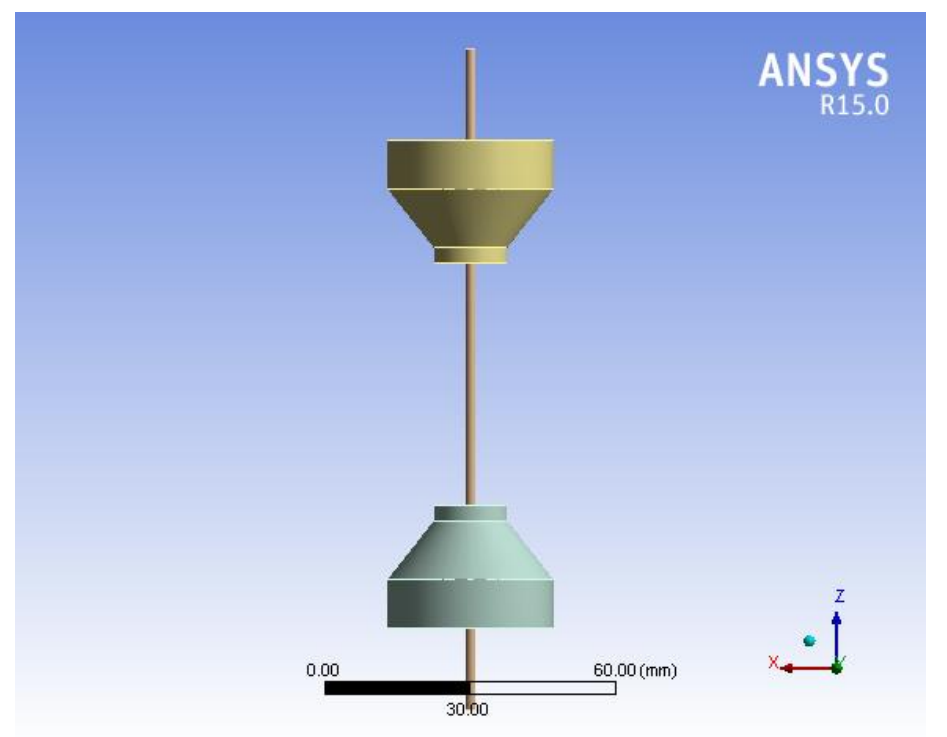

Fig. 4 CAD model of wire and wire guides 


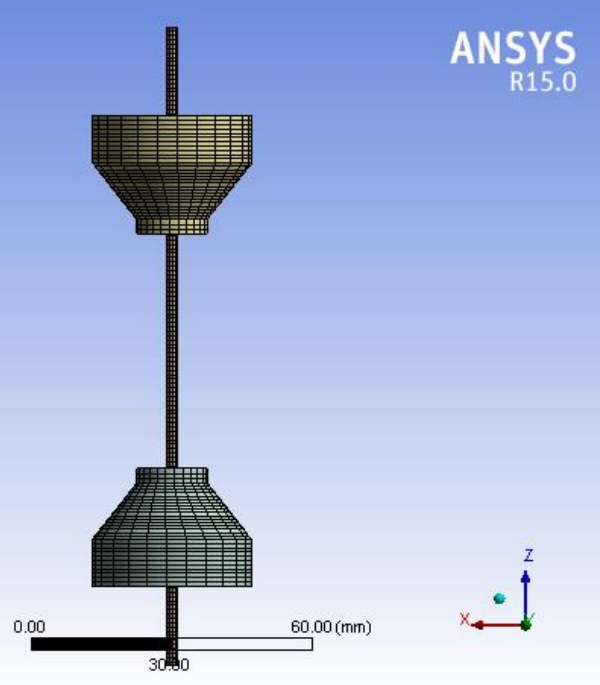

Fig. 5 Discretized Model

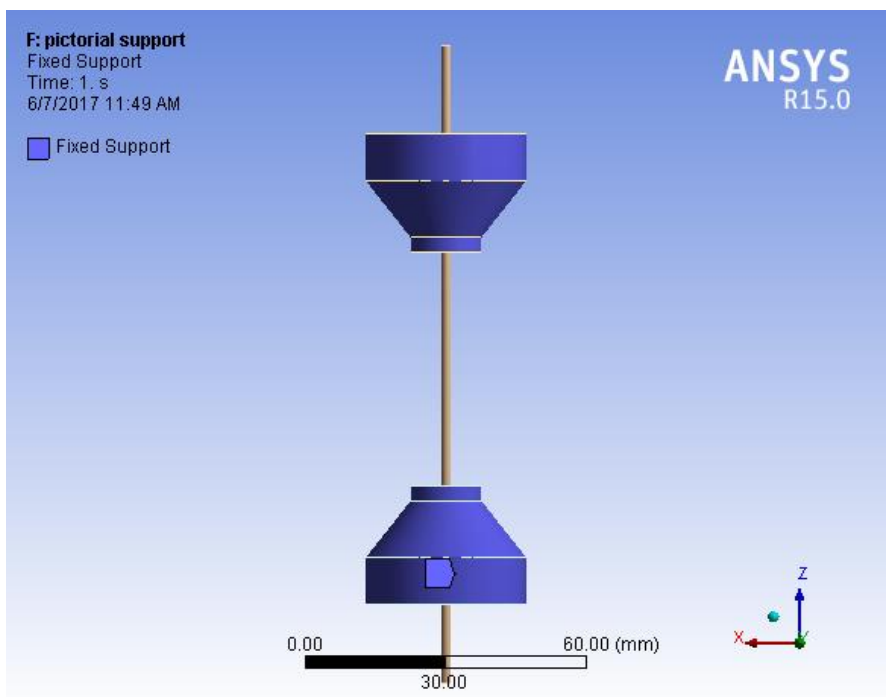

Fig. 6 Boundary Condition - Fixed Support

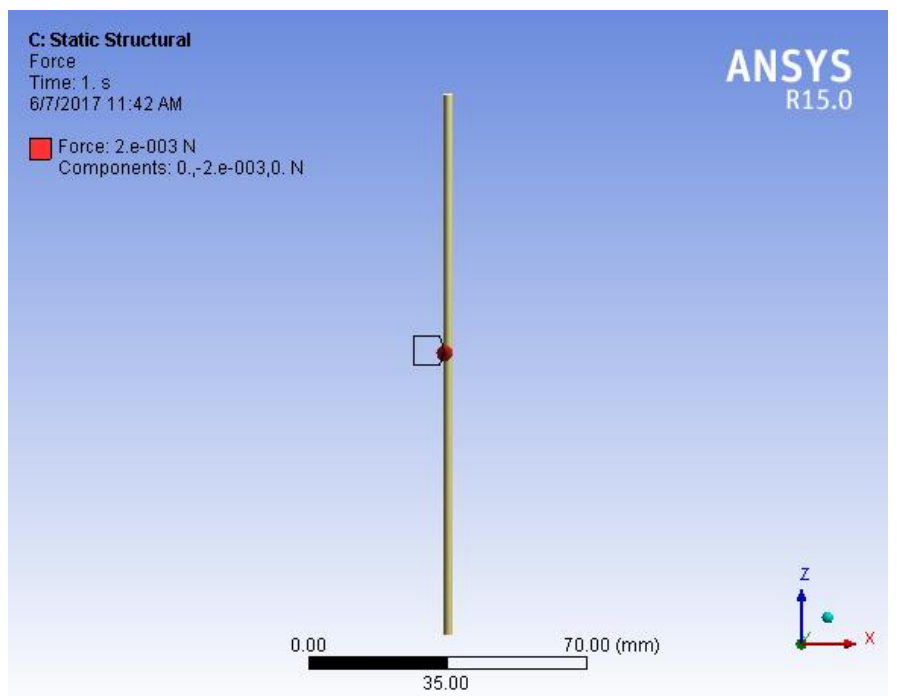

Fig. 7 Applying Force 

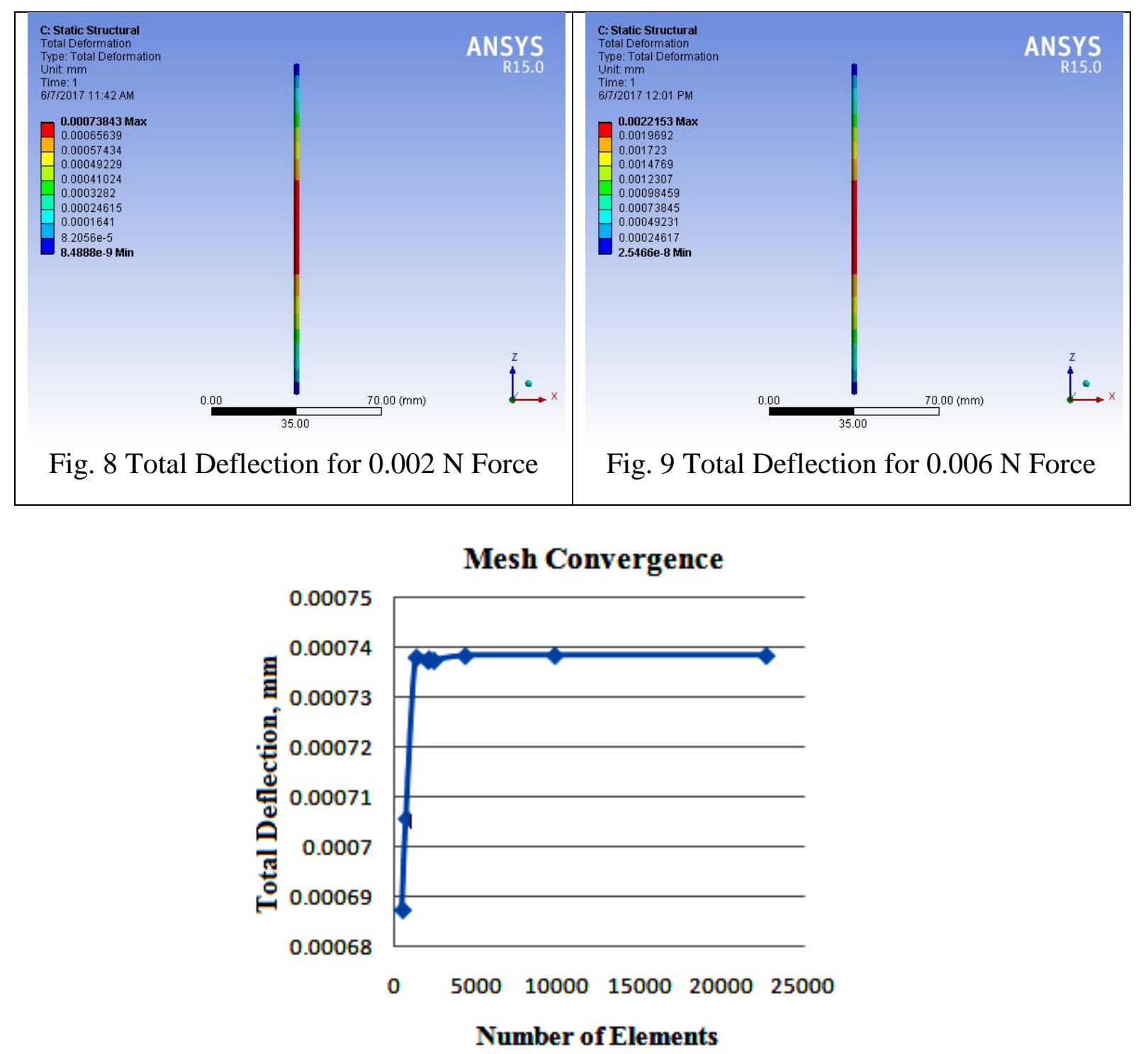

Fig. 10 Mesh Convergence Plot

Table 1: Total Deflection results from Finite Element Analysis

\begin{tabular}{|c|c|}
\hline $\begin{array}{c}\text { Applied Force } \\
\text { in N }\end{array}$ & $\begin{array}{c}\text { Total Deflection } \\
\text { in } \mu \mathrm{m}\end{array}$ \\
\hline 0.0005 & 0.1846 \\
\hline 0.0010 & 0.3692 \\
\hline 0.0015 & 0.5538 \\
\hline 0.0020 & 0.7384 \\
\hline 0.0025 & 0.9231 \\
\hline 0.0030 & 1.1077 \\
\hline 0.0035 & 1.2923 \\
\hline 0.0040 & 1.4769 \\
\hline 0.0045 & 1.6615 \\
\hline 0.0050 & 1.8461 \\
\hline 0.0055 & 2.0307 \\
\hline 0.0060 & 2.2153 \\
\hline
\end{tabular}




\subsection{Determining Frequency value}

Modal analysis has been performed with frequency of $50 \mathrm{~Hz}$ as per the machine specification for model as shown in Figure 3. The solution retrieved from the model to find the mode shapes are shown in Figures 11 to 14. From this, the frequency range of the model is found out, but in order to predict the resonance conditions (i.e. a frequency at which the component fails) the need for harmonic analysis arises. In the harmonic analysis, the force (i.e. a point load) is given as an input at the mid-span of the conductive wire as shown in Figure 6. Then the analysis is solved in order to find the frequency response curve as shown in Figures 15 and 16 for the $X$ and $\mathrm{Y}$ axis respectively. From the frequency curve, the maximum amplitude attained for the frequency value of $500 \mathrm{~Hz}$ in $\mathrm{Y}$ direction and $4500 \mathrm{~Hz}$ along $\mathrm{X}$ direction is attained. Hence, the obtained frequency value has been set as a reference for further calculation purpose.

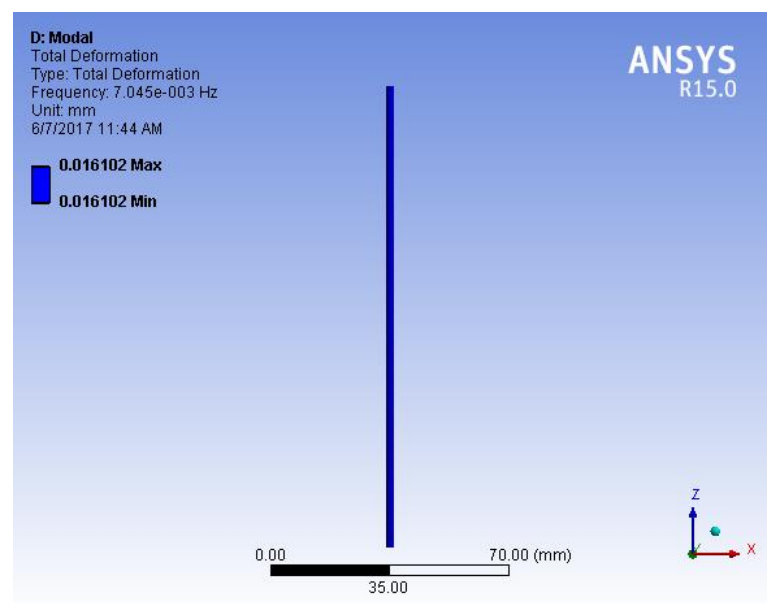

Fig. 11 Mode shape Result - $1^{\text {st }}$ mode

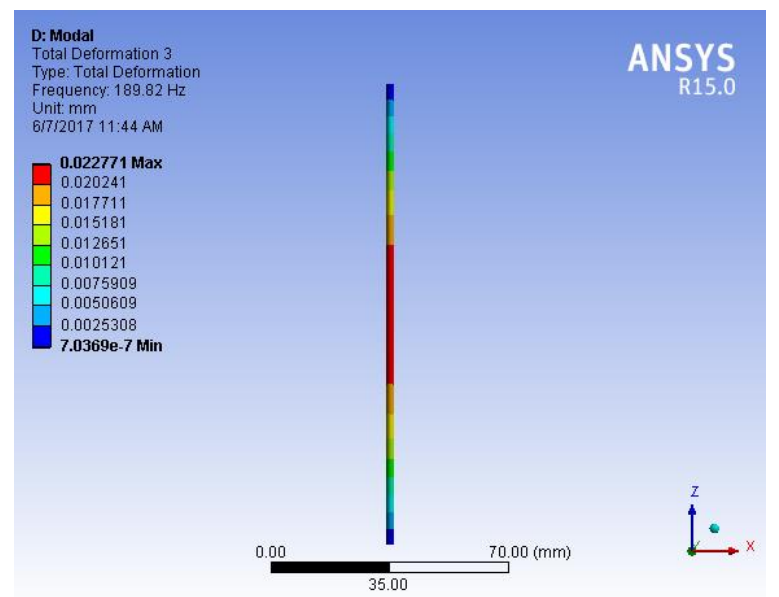

Fig. 13 Mode shape Result $-3^{\text {rd }}$ mode

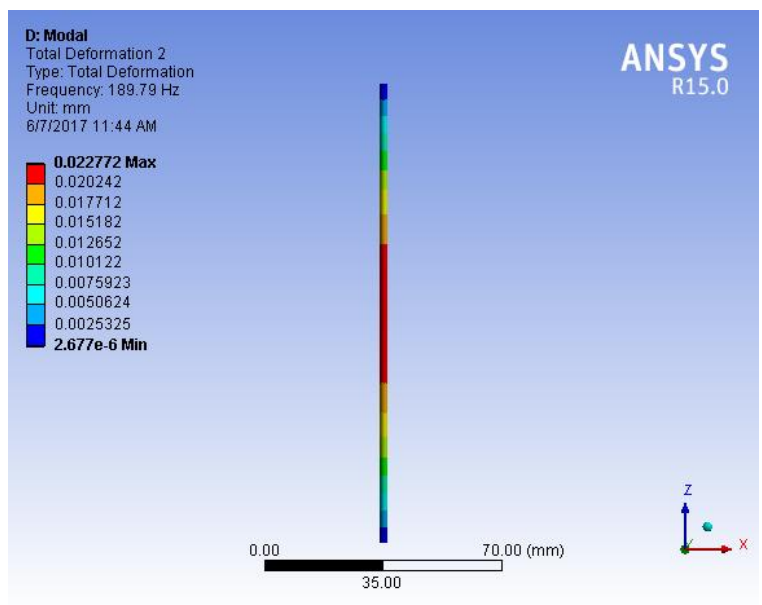

Fig. 12 Mode shape Result $-2^{\text {nd }}$ mode

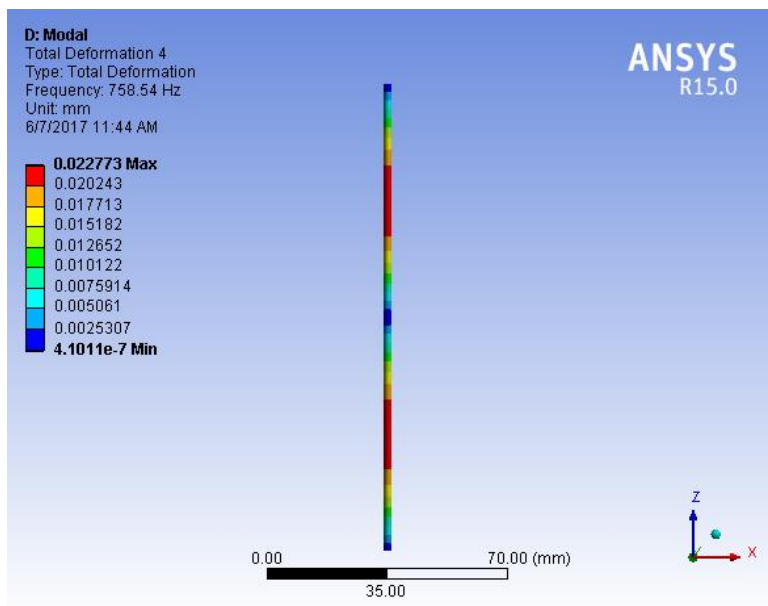

Fig. 14 Mode shape Result $-4^{\text {th }}$ mode 


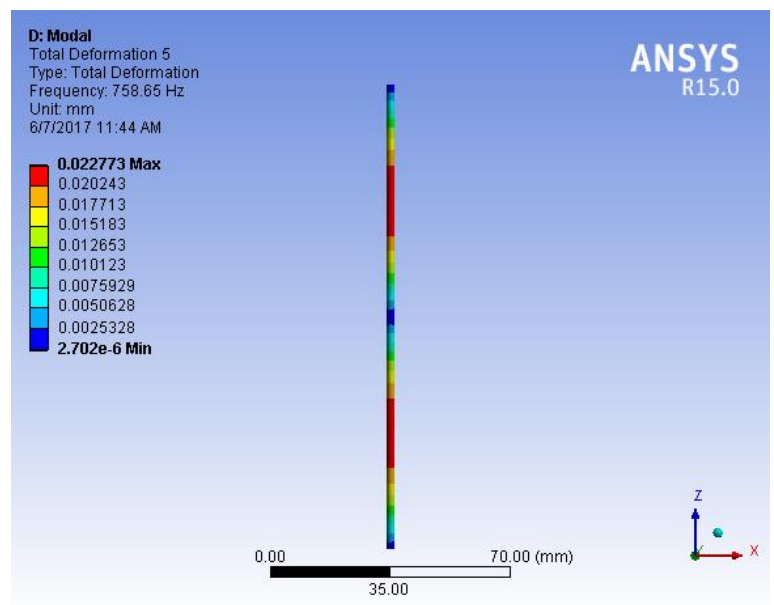

Fig. 15 Mode shape Result $-5^{\text {th }}$ mode

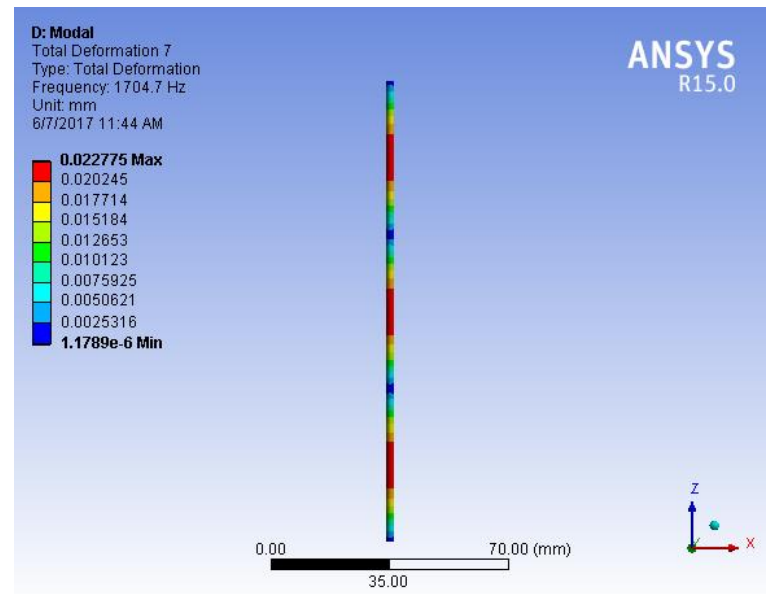

Fig. 17 Mode shape Result $-7^{\text {th }}$ mode

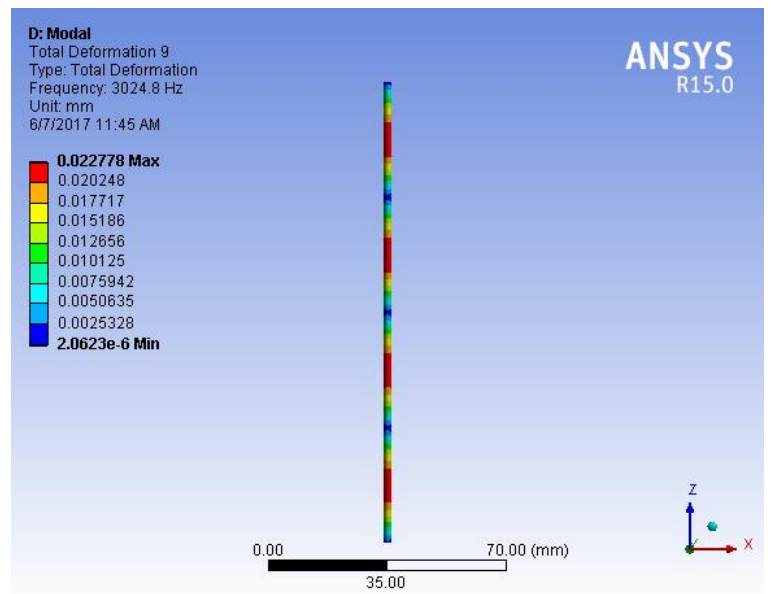

Fig. 19 Mode shape Result $-9^{\text {th }}$ mode

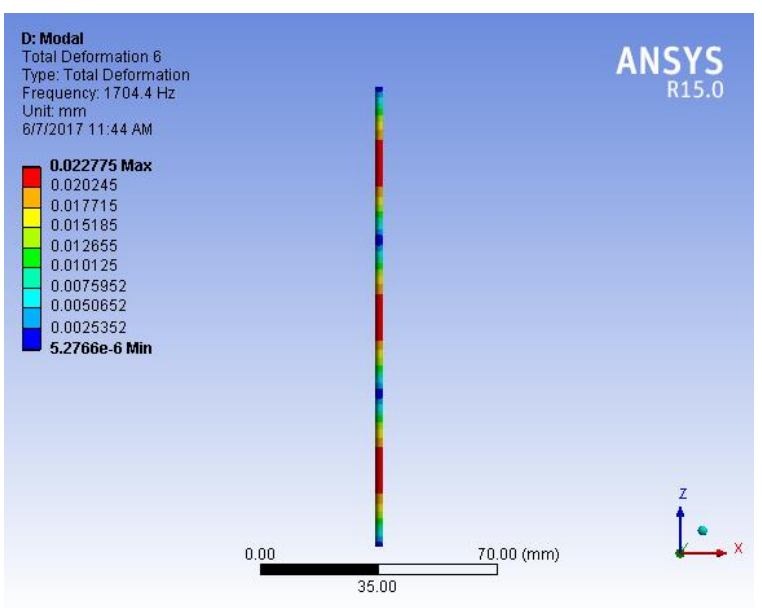

Fig.16 Mode shape Result $-6^{\text {th }}$ mode

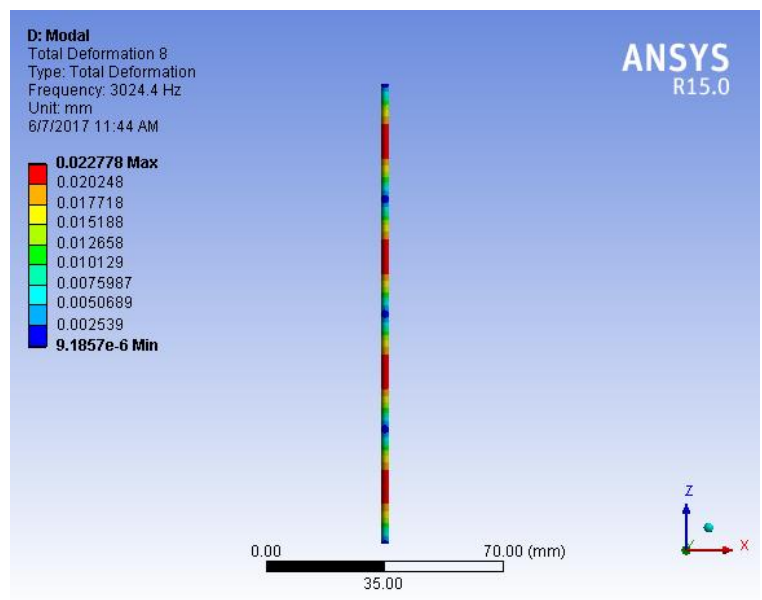

Fig. 18 Mode shape Result $-8^{\text {th }}$ mode

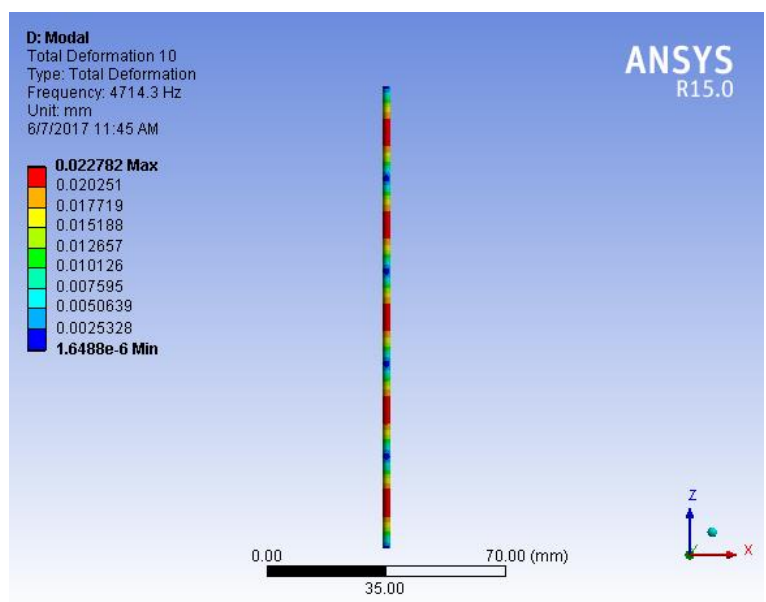

Fig. 20 Mode shape Result $-10^{\text {th }}$ mode 


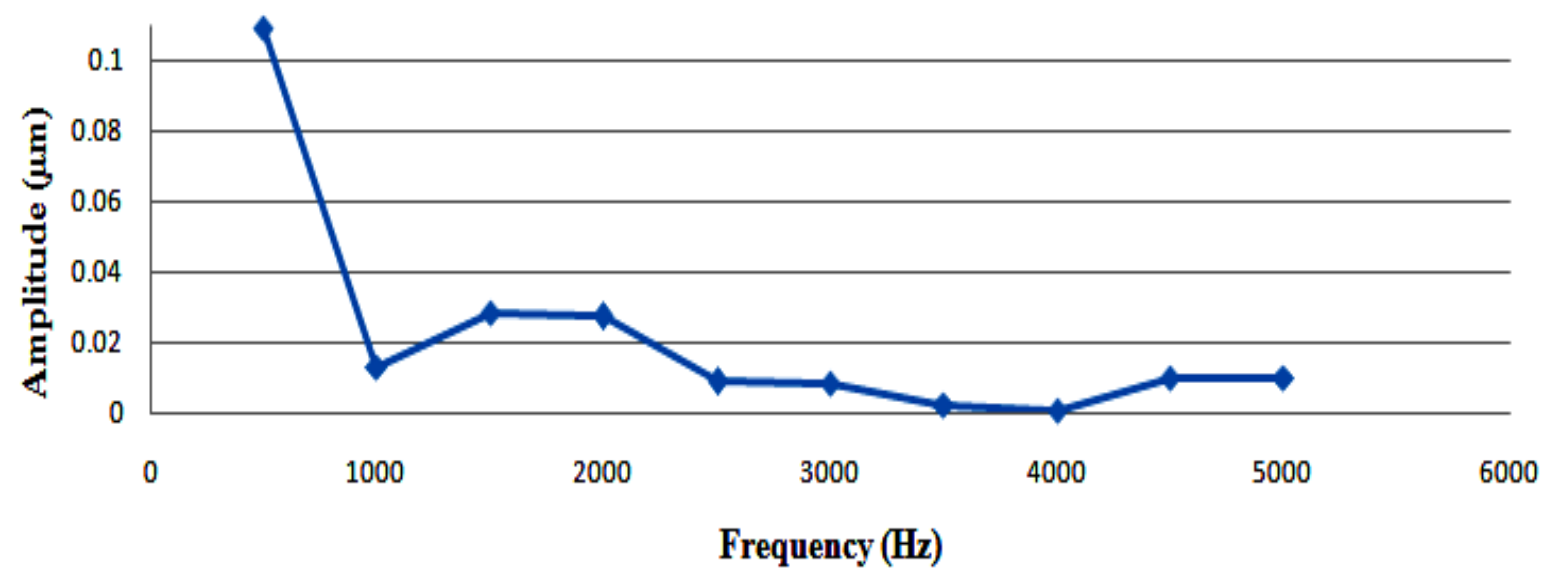

Fig. 21 Frequency Response Plot - Y Axis

Table 2 Frequency Response Values ( $\mathrm{X}$ and $\mathrm{Y}$ )

\begin{tabular}{|c|c|}
\hline $\begin{array}{c}\text { Frequency, X } \\
{[\mathrm{Hz}]}\end{array}$ & $\begin{array}{c}\text { Amplitude } \\
{[\mu \mathrm{m}]}\end{array}$ \\
\hline 500 & 0.00025 \\
\hline 1000 & 0.00028 \\
\hline 1500 & 0.00032 \\
\hline 2000 & 0.00024 \\
\hline 2500 & 0.00027 \\
\hline 3000 & 0.00031 \\
\hline 3500 & 0.00029 \\
\hline 4000 & 0.00032 \\
\hline 4500 & 0.00036 \\
\hline 5000 & 0.00031 \\
\hline
\end{tabular}

\begin{tabular}{|c|c|}
\hline $\begin{array}{c}\text { Frequency, Y } \\
{[\mathrm{Hz}]}\end{array}$ & $\begin{array}{c}\text { Amplitude } \\
{[\mu \mathrm{m}]}\end{array}$ \\
\hline 500 & 0.1092 \\
\hline 1000 & 0.0131 \\
\hline 1500 & 0.0284 \\
\hline 2000 & 0.0273 \\
\hline 2500 & 0.0089 \\
\hline 3000 & 0.0086 \\
\hline 3500 & 0.0024 \\
\hline 4000 & 0.0007 \\
\hline 4500 & 0.0097 \\
\hline 5000 & 0.0097 \\
\hline
\end{tabular}

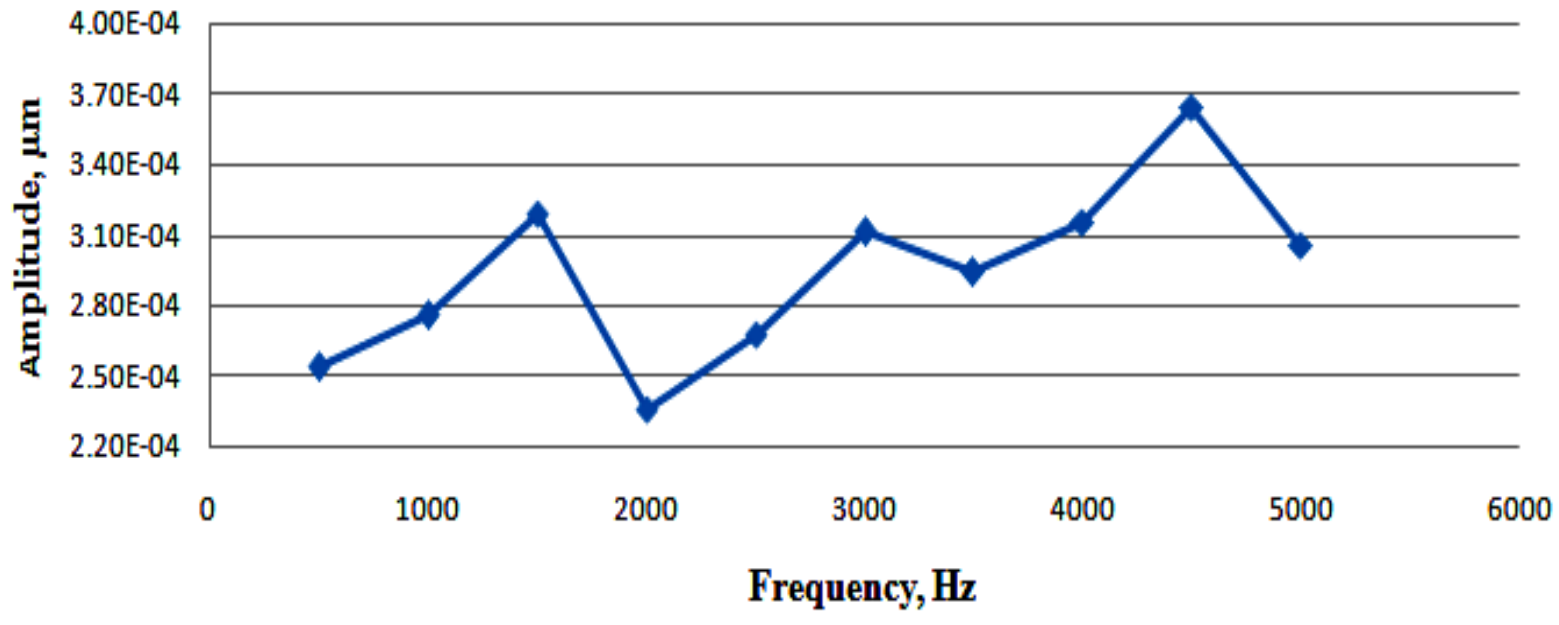

Fig. 22 Frequency Response Plot - X Axis 


\section{Multi-Discharge Modelling of Wire Vibration and Approach to obtain feasible Solution}

The work piece kept at the mid-position of the wire during machining [11]. The distance between the two wire guides is length $\mathrm{L}$, the length of the wire. The wire is displaced laterally through a distance over the height of work piece $\mathrm{H}$, due to the action of body force $q(z, t)$, as shown in the Figures 11 to 20 for different modes. The body force being the predominant one pushes the wire away from the work piece during collapsing of the spark discharges. The wire deflects through a distance of $a_{0}$ from its ideal initial stretched condition over the work piece height and the same is released at time ' $t$ '. The equation of motion, frequency, and the maximum amplitude of vibration of the wire under such condition was computed. The frequency responses of the given amplitudes have been shown in Figures $21 \& 22$ and the values for the same are given in Table 2. From the frequency response plot, it is noted that the deflection of amplitude in $\mathrm{Y}$ axis is high while starting the machine. The reason behind the rise of amplitude could be as the tensioned wire gets vibrated while the current is passed and that makes the amplitude to be high at the operating state from the static state. Similarly, in X axis, the maximum amplitude peak attained is at a frequency of $4500 \mathrm{~Hz}$, since the machine will not be excited at very high frequency and the deflection of wire across $\mathrm{X}$ axis is very minimal when compared to other axis. So the amplitude in $\mathrm{X}$ direction need not be taken seriously for consideration. Normally the uncertainty value of the CNC WEDG is within $\pm 0.005 \mathrm{~mm}$ as per the specification given by the manufacturer.

The displacement function $\mathrm{y}=\mathrm{y}(\mathrm{z}, \mathrm{t})[12]$ can be computed by solving the equation,

$$
\begin{gathered}
y(z, t)=e^{-\beta t / 2 \rho} \sum_{n=1}^{\infty}\left\{A \cos \left(\omega_{n} t\right)+B \sin \left(\omega_{n} t\right)\right\} \sin \left(\frac{n \pi}{L} z\right) \\
A=\frac{8 a_{0} L}{n^{2} \pi^{2}(L-H)} \sin \left(\frac{n \pi}{2}\right) \cos \left(\frac{n \pi}{2} \frac{H}{L}\right) \\
B=A \frac{\beta}{2 \rho} \frac{1}{\omega_{n}} \omega_{n}=\frac{1}{2} \sqrt{\left(\frac{4 n^{2} \pi^{2} F}{\rho L^{2}}-\frac{\beta^{2}}{\rho^{2}}+4 \alpha\right)}
\end{gathered}
$$

where, $\omega_{n}$ is the natural angular frequency of the wire vibration. The equation (2) is derived from the partial differentiation method $[12,13]$ where $\mathrm{A}$ and $\mathrm{B}$ are the constants for the amplitude of vibration of wire based on its angular frequency. Determination of plane stress was performed by static structural finite element analysis, by finite element simulation of strain gauge measurement, and by experimental measurement. Thin aluminum specimen with specific shape was tested. Results of finite element analyses and simulations were compared with experimental measurements results $[15,16]$.

In order to verify the finite element analysis results and the mathematical equation, a few calculations with the angular frequency of wire been done and the results are shown in Table 3.

Table 3 Comparison of Total deflection values

\begin{tabular}{|c|c|c|c|}
\hline \multirow{2}{*}{ Force, $\mathrm{N}$} & \multicolumn{2}{|c|}{ Total deflection value arrived, $\mu \mathrm{m}$} & \multirow{2}{*}{$\%$ Deviation } \\
\cline { 2 - 4 } & Finite Element analysis & Mathematical model [12] & \\
\hline 0.0020 & 0.7384 & 0.7577 & 2.55 \\
\hline 0.0025 & 0.9231 & 0.9475 & 2.56 \\
\hline
\end{tabular}




\begin{tabular}{|l|l|l|l|}
\hline 0.0030 & 1.1077 & 1.1346 & 2.37 \\
\hline
\end{tabular}

\section{Conclusions}

The numerical model for predicting the wire effects has been developed based on the working conditions of the Wire Electric Discharge Grinding and the same has been compared mathematically for sample values based on the equation derived by Herrero et al. (2008). It is found that there is a deviation of $2.56 \%$ which shows the correctness of the developed numerical model for the various forces. From the comparisons, it is found that the maximum excitation was found to occur on the $\mathrm{Y}$-axis, when compared to the excitation in the $\mathrm{X}$-axis. It is also found that the amount of deflection of the in the $\mathrm{Y}$ axis is below $2.5 \mu \mathrm{m}$ for both the numerical and analytical results.

\section{REFERENCES}

[1] M. I. Gokler, A. M. Ozanozgu. Experimental investigation of effects of cutting parameters on surface roughness in the WEDG process, International Journal of Machine tools \& Manufacturer 2000 (40), 1831 - 1848.

[2] C. V. S. Parmeswara, M. M. M. Sarcar. Evaluation of optimal parameter for machining brass with wire cut EDM, Journal of Scientific and Industrial Research, 2009 (68), 32 35 .

[3] W. J. Hsue, Y. S. Liao, S.S. Lu. Fundamental geometry analysis of wire electrical discharge machining in corner cutting, International Journal of Machine tools \& Manufacturer 1999 (39), 651 - 667.

[4] T. A. Spedding, Z. Q. Wang. Study on modeling of wire EDM process, Journal of Materials Processing Technology 1997 (69), 8 - 28.

[5] T. Masuzawa, M. Fujino, K. Kobayashi. Wire electro-discharge grinding for micro machining, CIRP Annals, 1985 (34), 431 - 434.

[6] E. Uhlmann, S. Piltz, D. Oberschmidt. Machining of micro rotational parts by wire electrical discharge grinding, Prod. Eng. Res. Development, 2008 (2), 227 - 233.

[7] A. Herrero, S. Azcarate, A. Rees, A. Gehringer, A. Schoth, A. Sanchez. Influence of force components on thin wire EDM, $4^{\text {th }}$ International Conference on Multi-Material Micro Manufacture 2008, Cardiff, UK.

[8] M. T. Yan, C. W. Huang, C. C. Fang, C. X. Chang. Development of a prototype micro Wire EDM machine, Journal of Mater. Process Technology 2003 (149), 99 - 105.

[9] V. K. Jain. Introduction to micromachining, 2010, Narosa, India.

[10] CMTI. Machine Tool Design Handbook, 1982 ,Tata McGraw-Hill, India.

[11] Chris Morgan, Shelby Shreve, R. RyanVallance. Precision of Micro Shafts Machined With Wire Electro-Discharge Grinding,Proceedings of the ASPE Winter Topical Mtg. On Machines and Process for Micro-scale, Meso-Scale Fabrication, Metrology and Assembly (28), 26 - 31.

[12] Calin Denes. An Overview of Wire Electrode Vibrations on WEDM, Nonconventional Technology review 2015 (19), 23 - 27.

[13] T. Veerarajan. Engineering Mathematics, 2006, Tata McGraw-Hill (Education) India. 
[14] M. Parthiban. Development of rotary axis for Wire Electrical Discharge Machining (WEDG), International Journal of Engineering Research, 2013 (2), No. 4, 314 - 317.

[15] R. Jančo, L. Écsi, P. Élesztős. FSW numerical simulation of aluminium plates by sysweld - Part I. Journal of Mechanical Engineering - Strojnícky časopis 2016 (66), No. 1, 47 52.

[16] P. R. Himanshu, P. Lalta, P. Mayank, T. Vineet. An estimating the effect of process parameters on metal removal rate and surface roughness in WEDM of composite Al6063/Sic/A12o3 by Taguchi method. Journal of Mechanical Engineering - Strojnicky časopis 2017 (67), No. 2, 25 - 36. 